\title{
The Formation of Carbon Microcoils Having the Coil-Type Overall Geometry
}

\author{
Gi-Hwan Kang and Sung-Hoon Kim*
} Center for Green Fusion Technology and Department of Engineering in Energy \& Applied Chemistry, Silla University, Busan
617-736, Republic of Korea

\begin{abstract}
Carbon microcoils could be synthesized using a thermal chemical vapor deposition process in which $\mathrm{C}_{2} \mathrm{H}_{2} / \mathrm{H}_{2}$ is used as the source gas and $\mathrm{SF}_{6}$ as an additive gas. We investigated the formation of carbon microcoils as a function of reaction time to study the growth mechanism of coil-type carbon microcoils, particularly under long reaction time. After the first $5 \mathrm{~min}$ of the reaction, wave-like carbon nanocoils were formed along with carbon microcoils at certain positions on the sample. An increase in reaction time $(60 \mathrm{~min})$ led to the formation of double helix-type carbon microcoils. Further increase in the reaction time $(120 \mathrm{~min})$ led to the formation of twist-type carbon microcoils with occasional growth of the coil-type carbon microcoils on the sample. However, at the longest reaction time (180 min) investigated in this work, we observed a decrease in the density of the carbon microcoils. Based on these results, we determine the optimal reaction time for the growth of double helix-type carbon microcoils and suggest the growth mechanism of the coil-type carbon microcoils with a focus on long reaction time.
\end{abstract}

Received on 16-10-2015 Accepted on 17-11-2015

Published on 05-01-2016

Keywords: Coil-type Carbon

Microcoils, Growth

Mechanism, Coil Geometry,

Reaction Time, Thermal

Chemical Vapor Deposition.

\section{INTRODUCTION}

Unique geometries of carbon microcoils have attracted considerable attention as a promising material in nano/microelectronic or mechanical devices [1-5]; however, the growth mechanism of carbon microcoils is not yet fully understood. Chen and Motojima reported the growth pattern and morphology development of carbon microcoils as a function of reaction time from 5 to $120 \mathrm{~min}$ [6]. Their study indicated that the initial reaction stage during carbon microcoil formation could play an important role in determining the geometry of the carbon microcoils. In general, metal catalysts are considered indispensable in the growth of carbon microcoils [7-10]. The catalytic anisotropy of the different crystal faces of the catalyst grain was proposed as the initial driving force to form the microcoil geometry [9] following a quasi-vapor liquid solid (VLS) mechanism [10].

A plausible growth mechanism of the carbon microcoils was also reported in our previous work [11-13]. Park et al. confirmed the initial stage of the reaction as being the most effective for the formation of the double helix-type carbon microcoils [11] Thus, the growth mechanism of the carbon microcoils was investigated from the preheating stage of the

"Center for Green Fusion Technology and Department of Engineering in Energy \& Applied Chemistry, Silla University, Busan 617-736, Republic of Korea; Tel: +82-51-999-5619; Fax: +82-51-999-5335; E-mail: shkim@silla.ac.kr reactor by Jeon et al. [12]. In their study, circular-type nickel clusters were formed when the substrate temperature was set to $750{ }^{0} \mathrm{C}$ followed by the formation of carbon nanofilaments after a reaction time of $30 \mathrm{~s}$. Jeon and Kim revealed that the twin carbon nanofilaments transformed into wave-like carbon nanocoils with an increase in the length of the carbon nanofilaments [13]. In spite of these reports, more in-depth investigation is still needed for complete understanding of the formation and growth mechanism of the carbon microcoils.

In this work, the surface morphology of the samples was investigated as a function of reaction time to study the growth mechanism of the carbon microcoils with various geometries at long reaction times. The evolution of the coil-type carbon microcoils from the double helix-type carbon microcoils was observed, particularly, at longer reaction time. To this end, we present a systematic growth model for the coil-type carbon microcoils with a focus on long reaction time.

\section{EXPERIMENTAL}

Silicon oxide $\left(\mathrm{SiO}_{2}\right)$ substrates used in this work were prepared by the thermal oxidation of $2.0 \mathrm{~cm} \times 2.0 \mathrm{~cm} \mathrm{p}$-type $\mathrm{Si}$ (100) substrates. The thickness of the $\mathrm{SiO}_{2}$ layer on the $\mathrm{Si}$ substrate was estimated to be about $300 \mathrm{~nm}$. About $0.01 \mathrm{~g}$ of nickel (Ni) powder (99.7\%) was evaporated for $1 \mathrm{~min}$ to form the $\mathrm{Ni}$ catalyst layer on the substrate using a thermal 
Table 1: The Detailed Reaction Conditions for the Formation of Carbon Microcoils

\begin{tabular}{|c|c|c|c|c|c|c|c|c|c|}
\hline \multirow[t]{2}{*}{ Samples } & \multirow{2}{*}{$\begin{array}{c}\mathrm{C}_{2} \mathrm{H}_{2} \\
\text { Flow Rate } \\
\text { (sccm) }\end{array}$} & \multirow{2}{*}{$\begin{array}{l}\mathrm{H}_{2} \text { flow } \\
\text { Rate } \\
(\mathrm{sccm})\end{array}$} & \multirow{2}{*}{$\begin{array}{c}\mathrm{SF}_{6} \text { Flow } \\
\text { Rate } \\
(\mathrm{sccm})\end{array}$} & \multirow{2}{*}{$\begin{array}{l}\text { Substrate } \\
\text { Temp. } \\
\left({ }^{\circ} \mathrm{C}\right)\end{array}$} & \multirow{2}{*}{$\begin{array}{c}\text { Total } \\
\text { Pressure } \\
\text { (Torr) }\end{array}$} & \multirow{2}{*}{$\begin{array}{c}\text { Reaction } \\
\text { Time(min) }\end{array}$} & \multicolumn{3}{|c|}{$\begin{array}{l}\text { Source/Additive Gas } \\
\text { Flow Time (min) }\end{array}$} \\
\hline & & & & & & & $\mathrm{C}_{2} \mathrm{H}_{2}$ & $\mathrm{H}_{2}$ & $\mathrm{SF}_{6}$ \\
\hline A & 15 & 35 & 35 & 750 & 100 & 1.0 & 1.0 & 1.0 & 1.0 \\
\hline B & 15 & 35 & 35 & 750 & 100 & 5.0 & 5.0 & 5.0 & 5.0 \\
\hline C & 15 & 35 & 35 & 750 & 100 & 60.0 & 60.0 & 60.0 & 5.0 \\
\hline D & 15 & 35 & 35 & 750 & 100 & 120.0 & 120.0 & 120.0 & 5.0 \\
\hline E & 15 & 35 & 35 & 750 & 100 & 180.0 & 180.0 & 180.0 & 5.0 \\
\hline
\end{tabular}

evaporator. The estimated thickness of the $\mathrm{Ni}$ catalyst layer on the substrate was about $400 \mathrm{~nm}$, as measured by cross sectional field emission scanning electron microscopy (FESEM).

A thermal chemical vapor deposition (CVD) system was used to grow carbon coiled structures, with acetylene $\left(\mathrm{C}_{2} \mathrm{H}_{2}\right)$ and $\mathrm{H}_{2}$ as the source gases. $\mathrm{SF}_{6}$, an incorporated additive gas, was injected into the reactor during the reaction. The flow rate for $\mathrm{C}_{2} \mathrm{H}_{2}, \mathrm{H}_{2}$, and $\mathrm{SF}_{6}$ were fixed at 15,35 , and 35 standard cubic centimeters per minute (sccm), respectively. The reaction processes were terminated at the desired reaction times. The substrate temperature and total pressure in the reactor were set to $750{ }^{\circ} \mathrm{C}$ and 100 Torr, respectively. The detailed reaction conditions for the formation of carbon microcoils are described in Table 1.

To elucidate the growth mechanism of the carbon microcoils at long reaction time, five samples (samples A-E) with different reaction times $(1,5,60,120$, and $180 \mathrm{~min})$ were prepared. Detailed morphology of the deposited carbon microcoils on sample substrates (A-E) was investigated by using FESEM (Hitachi S-4200).

\section{RESULTS AND DISCUSSION}

Figure 1 illustrates FESEM images of the surface morphologies of sample $A$. As seen in Figure 1a, a 1 min reaction resulted in the formation of carbon nanofilaments covering the entire surface area of sample A. The magnified images show several lumps (see Figure 1b) as well as the linear-type carbon nanofilaments which appeared to have a twin structure (see dotted circle in Figure 1c). Indeed, most of the carbon nanofilaments formed under this condition showed twin-structured carbon nanofilaments attached to each other, as discussed in our previous reports [12, 13]. In addition, many bright spots comprised of the $\mathrm{Ni}$ catalyst-incorporated carbon species, such as $\mathrm{Ni}_{3} \mathrm{C}$ were observed around the lump area [14].

Figure 2 shows FESEM images of the surface morphologies of sample B. After $5 \mathrm{~min}$ of the deposition reaction, we observed not only the formation of numerous wave-like carbon nanocoils but also the initial growth of the carbon microcoils on sample B (see areas marked by arrowheads in Figure 2b). We noticed that the formation of the carbon microcoils was initiated from the wave-like carbon nanocoils $[12,13]$.

As shown in Figure 3, after $60 \mathrm{~min}$ of the reaction, welldeveloped carbon microcoils were formed on the entire surface of sample $\mathrm{C}$. These carbon microcoils show the typical double helix geometry $[12,15]$ with lengths in the range of several tens of micrometers.

After $120 \mathrm{~min}$ of the reaction, double helix-type carbon microcoils were still observed on the surface of sample $D$, as seen in Figure 4. However, the density of the carbon
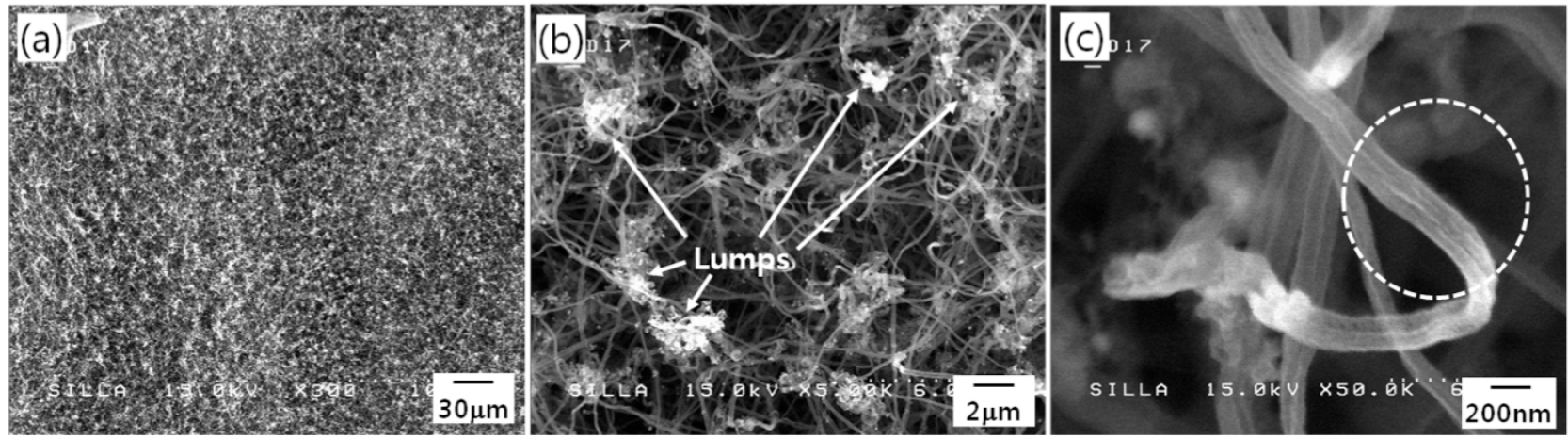

Figure 1: FESEM images of the surface morphologies for sample $A$ under the magnification of (a) 300 , (b) 5,000, and (c) 50,000 . 

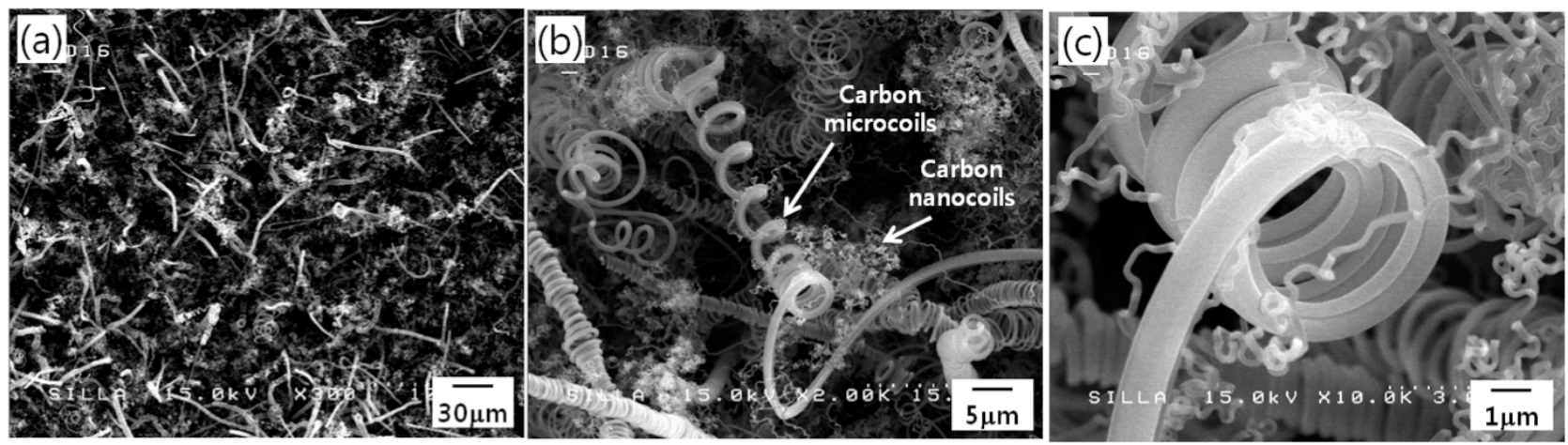

Figure 2: FESEM images of the surface morphologies for sample $B$ under the magnification of (a) 300 , (b) 2,000 , and (c) 10,000 .
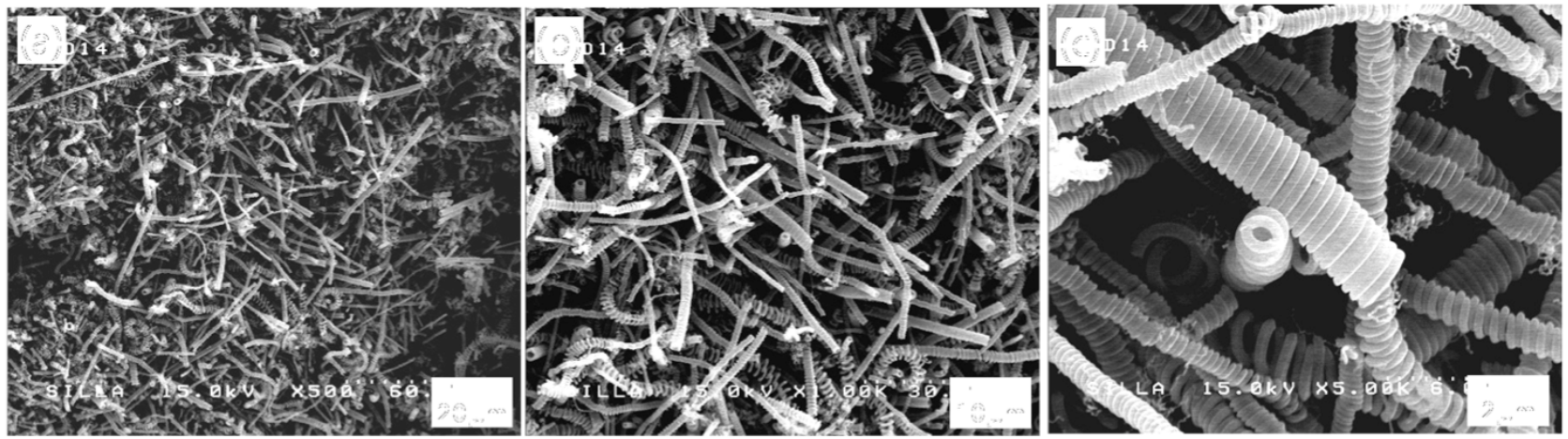

Figure 3: FESEM images of the surface morphologies for sample $C$ under the magnification of (a) 500 , (b) 1,000 , and (c) 5,000 .

microcoils was decreased compared to that observed after 60 min (compare Figures $\mathbf{4 b}$ and $\mathbf{3 b}$ ). In this case, many wavelike carbon nanocoils were also formed around the carbon microcoils as shown in Figure $\mathbf{4 d}$. In addition, compared to sample $C$, the length of the carbon microcoils in sample $D$ increased and reached more than several hundreds of micrometers (compare Figures $\mathbf{4 a}$ and $\mathbf{3 a}$ ). Besides the length difference, the overall geometry of the carbon microcoils was slightly different between sample $C$ and sample D. Specifically, the twist-type overall geometry for the carbon microcoils was commonly observed (see the dotted circle areas in Figures $\mathbf{4 b}$ and $\mathbf{4 c}$ ) along with occasional coil-
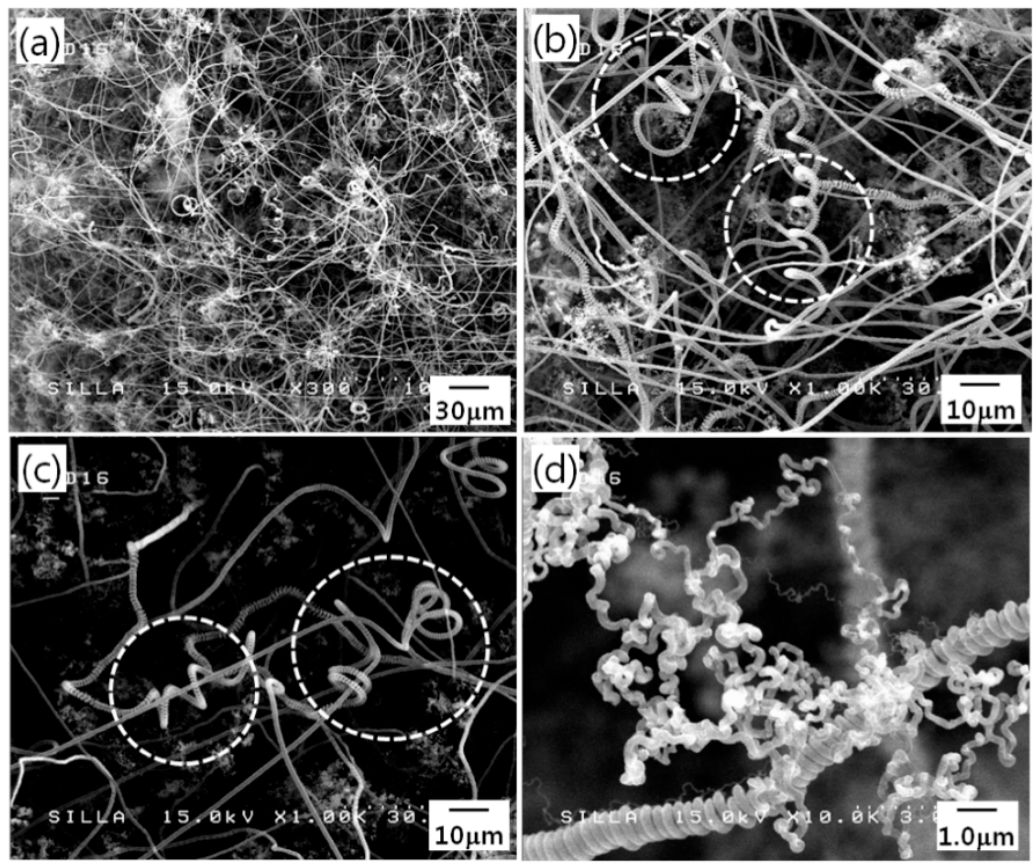

Figure 4: FESEM images of the surface morphologies for sample D under the magnification of (a) 300, (b) 1,000, (c) 1,000, and (d) 10,000 . 
type carbon microcoils on sample $D$ as shown in Figure 5. Our conclusion from the above observations was that the coil-type geometry evolved from the twist-type geometry.

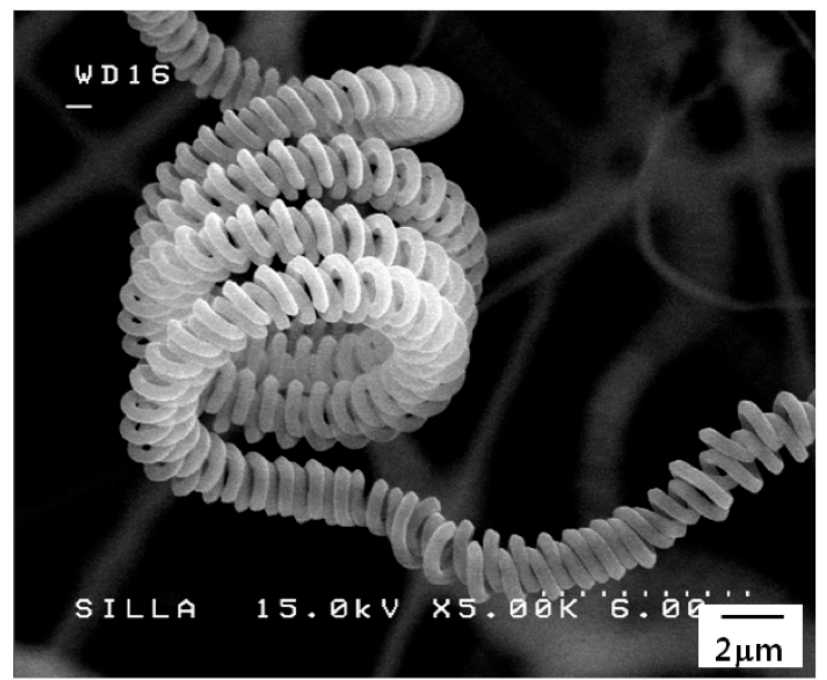

Figure 5: FESEM images of the carbon microcoil having the coil-type overall geometry.

Based on the results of Figures 1-5, we propose the following growth mechanism of carbon microcoils with a coil-type overall geometry from carbon nanofilaments with increasing reaction time: according to the dissolution-diffusionprecipitation model $[10,16]$, the precipitated carbon atoms are the origin for the growth of the carbon nanofilaments. In case of the formation of the carbon microcoils, the two carbon nanofilaments building up the double helix-type geometry were initiated from the coil's head with almost opposite growth direction [11]. The balance axis of the metal catalyst located on the coil's head was collapsed by the different growth rates of the two carbon nanofilaments. As a result, it caused twisting of the coil's head, further leading to the spinning of the coil's head. Moreover, the height difference between the starting points of the two carbon nanofilaments and the coil's head alternated for each carbon nanofilament as the coil's head advanced in its growth direction. The preceding steps led to the creation of carbon microcoils with double helix geometry. Further growth of the carbon microcoils causes twisting due to continuous spinning of the coil's head. Eventually, it leads to the formation of the coiltype overall geometry for the carbon microcoils. Figure 6 shows the systematic model for the formation of the carbon microcoils with the coil-type overall geometry.

For the longest reaction time (180 $\mathrm{min})$ investigated in this work, sample $E$ mainly showed linear-type carbon nanofibers
(1) Collapsing of the balance axis of the coil's head
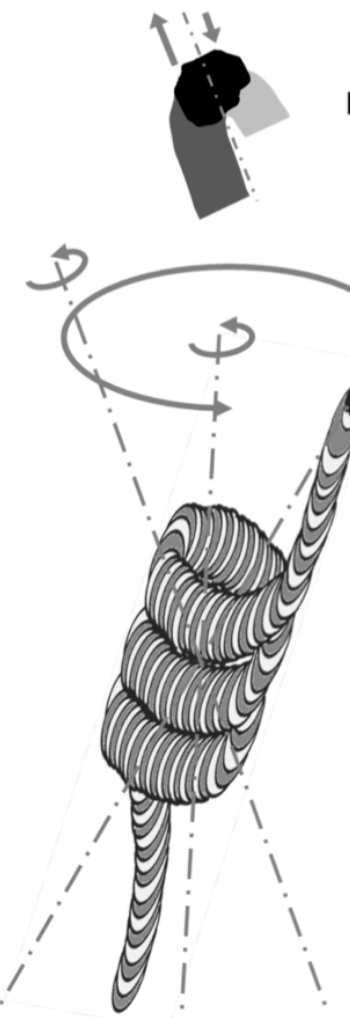

(6) Formațion of the coil type overall geometry
(2) Twisting of the coil's head
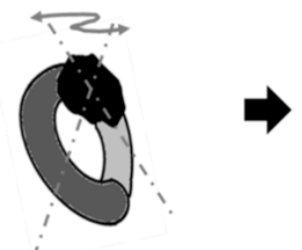

(3) Spinning of the coil's head

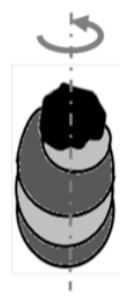

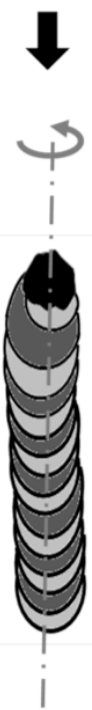

(5) Twisting of the entire carbon coils

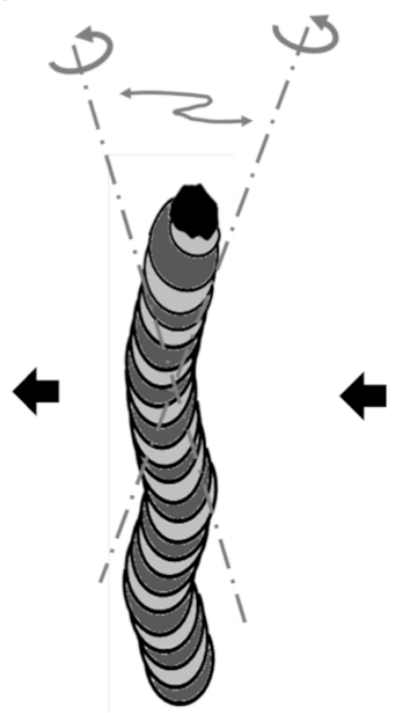

(4) Developing of the carbon microcoils

Figure 6: The systematic model showing the growth mechanism of the carbon microcoil with the coil-type overall geometry. 

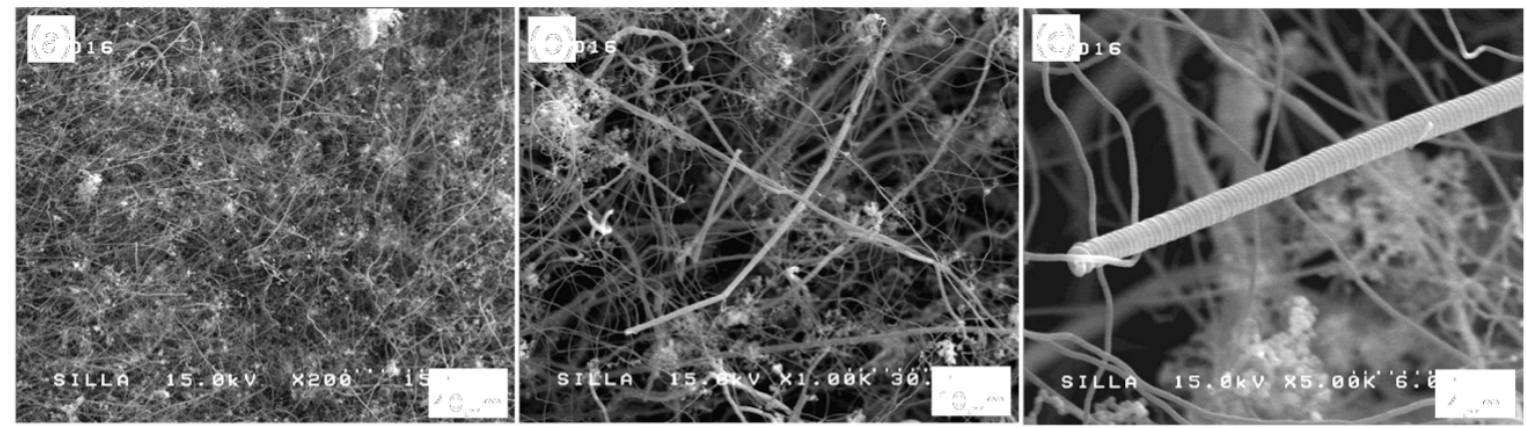

Figure 7: FESEM images of the surface morphologies for sample E under the magnification of (a) 200, (b) 1,000, and (c) 5,000.

with few carbon microcoils (Figure 7). These linear-type carbon nanofibers were formed via the release of the carbon microcoils. The release of the carbon microcoils was due to the continuous carbon feeding from the source gas $\left(\mathrm{C}_{2} \mathrm{H}_{2}\right)$, which consequently disrupted the spinning of the coil's head by the cumulative production of carbon materials on the head area. These results indicate that a reaction time of $180 \mathrm{~min}$ is not suitable for the formation of double helix-type carbon microcoils.

\section{CONCLUSIONS}

At the initial reaction stage (1 $\mathrm{min})$, twin-structured carbon nanofilaments were observed. At a reaction time of $5 \mathrm{~min}$, the formation of carbon microcoils was initiated among wave-like carbon nanocoils. At a reaction time of $60 \mathrm{~min}$, double helixtype carbon microcoils were formed with a higher density than any other stage of the reaction. At a reaction time of 120 min, the length of the carbon microcoils was increased and carbon microcoils having the twist-type overall geometry were formed. The twist geometry led to the formation of coil-type overall geometry due to the continuous spinning of the coil's head. We propose a systematic model for the formation of carbon microcoils with the coil-type overall geometry. At a reaction time of $180 \mathrm{~min}$, the density of the carbon coils was decreased, and instead, a large population of the linear-type carbon nanofibers was observed. These linear-type carbon nanofibers were formed due to uncoiling and untwisting of the carbon microcoils.

\section{ACKNOWLEDGEMENTS}

This work was supported by the Human Resource Training Program for Regional Innovation and Creativity through the Ministry of Education and National Research Foundation of Korea (2014H1C1A1066859).

\section{REFERENCES}

[1] Pan LJ, Hayashida T, Zhang M, Nakayama Y. Field emission properties of carbon tubule nanocoils. Jpn J Appl Phys 2001; 40: L235-7.

http://dx.doi.org/10.1143/JJAP.40.L235
[2] Amelinckx S, Zhang XB, Bernaerts D, Zhang XF, Ivanov V, Nagy JB. A formation mechanism for catalytically grown helix-shaped graphite nanotubes. Science 1994; 265: 635-9.

http://dx.doi.org/10.1126/science.265.5172.635

[3] Hokushin S, Pan LJ, Konishi Y, Tanaka H, Nakayama Y. Field emission properties and structural changes of a stand-alone carbon nanocoil. Jpn J Appl Phys 2007; 46: L565-7. http://dx.doi.org/10.1143/JJAP.46.L565

[4] Motojima S, Kawaguchi M, Nozaki K, Iwanaga H. Growth of regularly coiled filaments by $\mathrm{Ni}$ catalyzed pyrolysis of acetylene, and their morphology and extension characteristics. Appl Phys Lett 1990; 56: 321-3.

http://dx.doi.org/10.1063/1.102816

[5] Huczko A. Synthesis of aligned carbon nanotubes. Appl Phys A 2002; A74: 617-38.

http://dx.doi.org/10.1007/s003390100929

[6] Chen X, Motojima S. The growth patterns and morphologies of carbon micro-coils produced by chemical vapor deposition. Carbon 1999; 37 : 1817-23. http://dx.doi.org/10.1016/S0008-6223(99)00054-8

[7] Motojima S, Kawaguchi M, Nozaki K, Iwanaga H. Preparation of coiled carbon fibers by catalytic pyrolysis of acetylene, and its morphology and extension characteristics. Carbon 1991; 29: 379-85. http://dx.doi.org/10.1016/0008-6223(91)90207-Y

[8] Tang N, Wen J, Zhang J, Liu F, Lin K, Du Y. Helical carbon nanotubes: catalytic particle size-dependent growth and magnetic properties. ACS Nano 2010; 4: 241-50.

http://dx.doi.org/10.1021/nn901425r

[9] Chen X, Motojima S. Morphologies of carbon micro-coils grown by chemical vapor deposition. J Mater Sci 1999; 34: 5519-24. http://dx.doi.org/10.1023/A:1004768629799

[10] Kawaguchi M, Nozaki K, Motojima S, Iwanaga H. A growth mechanism of regularly coiled carbon fibers through acetylene pyrolysis. J Cryst Growth 1992; 118: 309-13.

http://dx.doi.org/10.1016/0022-0248(92)90077-V

[11] Park S, Jeon YC, Kim SH. Effect of injection stage of $\mathrm{SF}_{6}$ flow on carbon micro coils formation. ECS J Solid State Sci Technol 2013; 2: M56-9. http://dx.doi.org/10.1149/2.004312jss

[12] Jeon YC, Ahn SI, Kim SH. Developing aspect of carbon coils formation during the beginning stage of the process. J Nanosci Nanotechnol 2013; 13: 5754-8. http://dx.doi.org/10.1166/inn.2013.7040

[13] Jeon YC and Kim SH. Development of the geometry of carbon microcoils from carbon nanofilaments. Vacuum 2014; 107: 219-24. http://dx.doi.org/10.1016/i.vacuum.2014.02.008

[14] Yang S, Chen C, and Motojima S. Morphology of the growth tip of carbon microcoils / nanocoils. Diamond Relat Mater 2004; 13: 2152-5. http://dx.doi.org/10.1016/i.diamond.2004.06.014

[15] Eum JH, Kim SH, Yi SS, and Jang K. Large-scale synthesis of the controlled-geometry carbon coils by the manipulation of the $\mathrm{SF}_{6}$ gas flow injection time. J Nanosci Nanotechnol 2012; 12: 4397-402. http://dx.doi.org/10.1166/inn.2012.5940

[16] Rodriguez NM. A review of catalytically grown carbon nanofibers. J Mater Res 1993; 8: 3233-50.

http://dx.doi.org/10.1557/JMR.1993.3233 